\title{
Environmental Accounting: Theoretical Review and Enlightenment for China
}

\author{
Jiale Zhang ${ }^{1}$ \\ ${ }^{1}$ College of Economics \& Management, Nanjing Institute of Industry Technology, Nanjing, China \\ Correspondence: Jiale Zhang, College of Economics \& Management, Nanjing Institute of Industry Technology, \\ Nanjing, No.1 Yangshan North Road, 210023, China. Tel: 86-25-8586-4220. E-mail: zhangj12@niit.edu.cn
}

\author{
Received: November 26, 2013 Accepted: December 12, 2013 Online Published: February 25, 2014 \\ doi:10.5539/jms.v4n1p179 URL: http://dx.doi.org/10.5539/jms.v4n1p179
}

\begin{abstract}
This paper generalizes with emphasis the main literatures on the theory of environmental accounting in recent years, and tries to review the new development of researches on environmental accounting of the international academic circles from a viewpoint in five aspects of sustainability, externalities, information disclosure, cost management and behavior science according to the development course and logical relationship of the literatures. The thesis discusses the inner links between the five aspects and development direction of the related theories, and analyzes the latest trends of methods and contents of the current theoretical research in environmental accounting, so as to provide reference and enlightenment for the perfection of environmental accounting theory in China. Finally, it puts forward the direction of further research combining with the current research status of the theory of China.
\end{abstract}

Keywords: environmental accounting, theoretical evolution, recent development, enlightenment

\section{Introduction}

Sustainable economic growth requires that the development of enterprises be coordinated with their environmental responsibility. Environmental accounting, as a tool of reflecting and supervising environment-related economic activities, falls into the category of accounting from the early 1970s, represented by papers titled Research on Conversion of Social Costs in Pollution Control written by F. A. Beams in1971 and Accounting Problems of Pollution written by J. T. Malin in 1973, which open the prelude of the research in environmental accounting (Zhu, 1999). The report of United Nations World Environment and Development Committee titled "Our Common Future" in 1987 and the UN Conference on Environment and Development in 1992 made the research and discussion on environmental accounting get more and more attention and concern. Since then, scholars have launched in-depth research and discussion in environmental accounting, "Green accounting: the accounting profession after Pearce" issued by Rob Gray in 1990 is recognized as a milestone in the research of environmental accounting, which marks that the research in environmental accounting has become the central subject under discussion in the global academic circles. Gray (1990) argues that the connotation of environmental accounting is "accounting about increase or decrease on artificial assets and natural assets, most importantly accounting of conversion between the two assets". That is, environmental accounting mainly studies and discloses artificial assets, natural assets and conversion between these assets. After that, there are two kinds of mainstream viewpoints on the definition of environmental accounting. One view holds that environmental accounting plays a role of "book noting", that is, accounting is a tool .measuring the economic performances of a company or a country. For example, Peskin \& Angeles (2001) argues that environmental accounting refers to the adjustment over the traditional measurement methods of economic performances (such as GDP, NDP, GNP or NNP), in order to make the measurement methods reflect the change of natural environment better. The other view emphasizes the management functions of environmental accounting. For instance, Steele \& Powell (2002) consider that environmental accounting is to confirm, distribute and analyze material flows and related cash flows through the use of the environmental accounting management system, making managers recognize the environmental and financial impacts of the enterprises.

With the deepening and development of the research on environmental accounting, scholars try to make theory innovation and exploration in environmental accounting from different perspectives, and the understanding over environmental accounting has also been further extended. Gray \& Bebbington (2001) point out that 
environmental accounting is not confined only to enterprise accounting. Hines (1988), Solomon \& Thomson (2009) maintain that environmental accounting should also have certain characteristics such as empiricalness, systematicness, transparency, objectivity, reliability, intelligibility, verifiability, auditability and fairness, etc. Solomon \& Thomson (2009) expand the concept of environmental accounting, maintaining that environmental accounting refers to a system which provides inflow and outflow information for different entities and congregates natural, economic, cultural, ethical and social resources in order to measure the environmental efficiency and social efficiency of different entities.

It can lay theoretical foundation in building environmental accounting system for China to make use of the worldwide attention paid to the problems on global climate, environmental resources and social development (Liu, 2011). In the academic circle, there are very rich results on theoretical research in environmental accounting. It can provide helpful background knowledge and academic standpoint for the related researches in China by combing clearly these achievements and on the basis reasonably using for reference and absorbing these achievements. This paper attempts to review the new development of environmental accounting theory from aspects of sustainability, externalities, information disclosure, cost management and behavior science and points out the possible future research directions combining with the research situations in China so as to provide experiences and references for further research on environmental accounting theory

\section{Some Development in Environmental Accounting Theory}

From the latest research literatures, the researches on environmental accounting theory in recent years enrich the theoretical basis in environmental accounting and reporting, develop related technologies and methods of environmental accounting, and conduct in-depth research from different viewpoints. There is some progress made in several aspects as follows.

\subsection{Development from the Perspective of Sustainability}

Sustainable development is a new development concept occurring in the 1970s. It is a strategic pattern of the long-term development for mankind based on the natural ecological environment resources. The proposal of the strategy is results with positive significance on the human's exploration of how to develop in reason, which will produce profound influence on the development of the human society and economy. There is no doubt that traditional accounting cannot provide sufficient information for the sustainable development of enterprises or reflect the special contributions to sustainable development made by them (Maunders \& Burritt, 1991).

The literatures that initially connect accounting with sustainability focus mainly on the deficiency of traditional accounting (Schtegger \& Sturm, 1992; Mhews, 1997) and the potential limitation of accounting system (Gray, 1992; Lehman, 1999). But in the early days, sustainable accounting is not fully conceptualized. It only has a vague description at most, and is just another pronoun of environmental accounting or environmental reporting (Lamberton, 2005). Gray \& Milne (2002) proposed that enterprise sustainable accounting and reporting is accounting that emphasizes services to ecological system and society and that considers the ecological justice and pays attention to efficiency and effectiveness. In Britain, Prince Charles has launched an Accounting for Sustainability Project (ICAEW, 2008), which conducts systematical research on problems of long-term sustainable development of enterprises and how to integrate sustainable development into enterprise management. Schahegger \& Burritt (2010) put forward again clearly the concept of "sustainability accounting" and pointed out that it is a branch of accounting, which serves ecological system and society, and that sustainability accounting, as an information management tool and method, can promote the development of enterprise sustainability and corporate responsibility. Therefore, the difference between sustainability accounting and traditional accounting lies in the fact that sustainability accounting provides adequate relevant information about sustainable development of enterprises and the specific contributions enterprises made to sustainable development. What sustainability concerns about is the relationship between and interactions among society, environment and economic sustainable development. For example, a specific economic system (such as an enterprise or the state, etc.) will have an impact on the ecological environment and society, and the environment and society will influence finance. The role of sustainability accounting is to record, analyze and report these effects by use of related methods and system.

The specific reasons that motivate managers to build an accounting system to provide behavior information for the evaluation of sustainable development of the company, in addition to the essential motivation of managers and the importance of accounting to sustainable development of the corporation, include the following five major factors: propaganda of green enterprise (Gray, 2006), imitation and industrial pressure (Schahegger et a1., 2005), pressures from the law, shareholders and business license (Cooper \& Owen, 2007), enterprise self-discipline (Gunningham, 2007) and corporate responsibility and ethical factors (Ashman \& Winstanley, 
2007).

According to the existing literatures, the explanations based on the viewpoint of sustainable development lay particular stress on the construction of macroscopic theory, mainly focus on the relationship between and roles of the enterprise and society, environment and economy from the height of strategy The relevant literatures mainly expound the positioning, functions and motivations of sustainability accounting, and emphasize the importance of non-financial information and management. However, the current studies only point out that sustainability accounting is the extension and development direction of environmental accounting, but do not clarify the specific differences between sustainability accounting and the existing environmental accounting at the operating level, nor put forward a specific framework or system of sustainability accounting.

\subsection{Development from the Perspective of Externalities}

Pigou (1920) put forward the problem of pollution externalities. He made a clear distinction between marginal net private product and marginal net social products (including external costs), and called the balance between the two items externalities in which the balance is the external costs produced by private economic activities. The theory of externalities discloses the external properties of the pollution problem in the sense of economics, and thus lays a theoretical foundation for later generations to solve the environmental problems by economic (or market based) methods. In regard to the externalities problem, Coase (1960) put forward the famous Coase theorem: As long as property right is clear, the externalities problem can be solved through compensation after consultation, so as to realize the internalization of the external problems.

On the environmental issues, pollution discharging enterprises produce negative externalities to the society and other enterprises. In order to solve the negative externalities, measures must be taken to make the externalities internalized. The externality theory holds that resource allocation of the market cannot be efficient if there are certain goods that can not be marketized, or some costs that are not considered by individuals as buyers or sellers. Dales (1969), under the inspiration of Coase theorem, put forward pollution rights trading theory, which has made great contribution to solve the problem of environment pollution. Its basic idea is to take the government as the owner of the public resources and the representative of public interests, and to sell publicly a certain amount of pollution rights according to allowed emissions per unit in the market within the scope that environmental pollution can be controlled. Montgomery (1972) conducted further research on the issue in-depth and put forward the first theory of strict trading license rights. He studied the economic basis of emission rights trading, argued that the trading license system can provide in some sense an effective policy tool for emission control, and explained with a strict theoretical model the effectiveness of solving all kinds of pollution effectively in a marketized manner which enhanced the influence in solving the problem of pollution with property measures.

With the development of the research on emission rights theory and practice, some scholars notice that a reasonable initial allocation of emission rights, trading system and a scientific and reasonable emission rights pricing mechanism are important factors that influence the market performance of emission rights. They decide to a large extent the market volume and active degree of emission rights trading. Woerdman (2002) maintained that the irrationality of initial allocation of emission rights, arbitrary and subjective pricing and the price blindness of later transaction could cause the emergence of an invalid market. If pricing is too low, there will no incentive effect to the low pollution or pollution free enterprises; if pricing is too high, it will prevent the emission rights trading market from functioning effectively. Maeda (2001), based on the $\mathrm{SO}_{2}$ emission rights market price in the United States, developed an analysis framework of the pricing model of GHG (Greenhouse Gas) market forward contract and at the same time made an investigation into the influence of storage mechanism on the spot and the forward market prices. Sijm et al. (2006) studied the pricing mode of carbon emission license in Germany and Holland and problems such as opportunity costs of the license. Bebbington \& Larrinaga-gonzalez (2008) discussed problems on confirmation and valuation related to greenhouse gas emissions license, for example the identifying of EUA (EU emission license) as assets. Mete et a1. (2010) deemed that the basis of emission rights trading system is that the market becomes the efficient distribution method of carbon license resources. They discussed, from the angles of accounting and tax law respectively, the significance of carbon emission rights in the system. Linaquist \& Goldberg (2010) argued that it will produce the problem of accounting fraudulent practices in the cap-and-trade system, such as increasing the base, not fully reporting of carbon emission rights, excessive reporting of making up for carbon emission credits and corruption. Kijima et a1. (2010) put forward a model and a pricing formula concerning the emission rights trading license market.

In addition, some scholars also support the levy of environment tax to control environmental pollution. Ihmann 
(2009) considered that "external cost internalization" is the solution to environmental problems, and that the specific measure to internalize the externalities is to implement the system of emission rights trading license and to levy environment tax. Davis and Muehlegger (2010) argued that authoritative method to solve externalities is to use Pigou tax (i.e., environment tax) or adopt method similar to amount-trading (cap-and-trade) plan.

It can be seen that the aim of the research on environmental accounting based on the theory of externalities is to solve the environmental problems brought about by negative externalities of pollution enterprises, which provides specific methods and measures to solve the externalities problem and has practical significance and application value. Related researches put theory into practice and have an important significance in guiding the implementation of emission rights trading and the collection of environment tax. It is worth noting that most researches are based on the backgrounds of western developed countries, in which there are a clear property rights system, mature market economy system and perfect legal environment. Therefore, the application premise of the theory is that there must be active participations of the government or authoritative organizations in it, and that canonical regulations and files are established to ensure the implementation effect.

\subsection{Development from the Perspective of Information Disclosure}

In recent years, literatures of environmental accounting have developed many theories to explain environmental information disclosure behaviors of enterprises. Clarkson et a1. (2008) divided the theories into two categories, and defined them as voluntary disclosure theory and social-political theory respectively. Among them, the voluntary disclosure theory holds that the aim of enterprise voluntary disclosure is because the environmental performance can transfer information to shareholders (Li et a1., 1997; Bewley \& $\mathrm{Li}, 2000$ ). They use objective environmental performance as a way to transfer information, expect that the content of the disclosure of environmental performance can be positively related to environmental performance, and hope to transfer the environment strategy of the enterprise to shareholders through environmental disclosure (Clarkson et a1., 2008).

The second theory is social-political theory, which consists of a political-economy theory, shareholders theory and legitimacy theory (Gray et a1., 1996; Deegan, 2002). Guthrie and Parker (1990) were the first to use the concept of political-economy theory in environmental accounting disclosure. Maltby (2004) gave the theory more accurate description: enterprise disclosure of social environment report is not just to show their obedience to the present criterions and rules but also the special and important value of the enterprises, so enterprises have initiatives to improve their value to society and do not just response to the needs of the society. Freedman and Jaggi (2010) made comparison with GHG disclosure of the contracting parties of Kyoto protocol. The test results show that the motivations described in political-economy theory can promote the disclosure of GHG. Shareholders theory maintains that disclosure of environmental information is due to the fact that managers provide information in order to meet the needs of the shareholders (Ullmann, 1985; Robeas, 1992), The theory is one of the main social report theories, which is widely used in literatures of social environment accounting and reporting (Adam, 2002; Deegan \& Blomquist, 2006). If what shareholders theory considers is the relationship between the enterprise and specific shareholders, legitimacy theory however focuses on the relationship between the enterprise and the society. Legitimacy theory is the most common approach adopted by scholars to explore the theory of corporate social environment report (Deegan et a1., 2000, 2002). According to legitimacy theory, enterprises try to reflect expectations the society show to them (Dowling and Pfeffer, 1975; Patten, 2000). That is, enterprises hope the public take their activities legal through environmental information so as to reduce social pressure on them. But in fact, enterprise behaviors may run counter to the report. The major difference between shareholders theory and legitimacy theory is that the essence of the disclosure is different. In shareholders theory, companies disclose information that can be received by shareholders and the information is consistent to actual condition of them. While in legitimacy theory, companies provide information that can make the shareholders satisfied, but this information does not reflect the real performance, nor help shareholders make the right decisions.

The empirical researches attempt to test the factors that affect environment information disclosure, and the conclusions are mot the same. The results show that policy factors play an important role in environment information disclosure. Take the United States as an example; some evidences indicate that policy pressures from SEC have obviously promoted the environmental disclosure since the 1990s (Stagliano et a1., 1998). In Australia, the government stipulates in 1998 that companies must report environmental performances on the annual report. Frost (2007) selected companies as samples that may be affected most probably by the influence of the clause, such as environment sensitive industries of resources (ore mining, oil and natural gas), infrastructure, papermaking and packaging, and made analysis over the sample companies by using content analysis method. The study found out that the law has had a positive effect in environmental disclosure of 71 companies in Australia. After Kyoto protocol that aims to limit greenhouse gas emissions came into force in 2005, many 
scholars have studied the effect of the agreement on enterprises. Freedman \& Jaggi (2010) studied whether the signing of the Kyoto protocol has promoted the performance in greenhouse gas emissions and related disclosure. They think that the signing of the agreement and limitation of GHG will motivate managers to improve performance in pollution control to reach the requirements of the agreement, and therefore there will be good GHG disclosure. What's more, the approval of the agreement can improve investors' expectations for the performance in GHG, and then better market expectations will provide managers with additional incentives to improve the company's disclosure. So the authors assume that enterprises from the agreement signing countries (such as the European Union, Canada, Japan and India), especially states that set up the GHG limit have better GHG performances and disclosure than those in non agreement signing countries (such as the.US). They select 510 companies as samples that may affect global warming from the top 2000 companies in global Forbes ranking in the sample countries, and evaluate GHG disclosure of the companies using content analysis approach through questionnaire in Carbon Disclosure Program (CDP) and disclosure in website, company annual report and report on social environment and sustainable development. The study shows that the GHG disclosure of US is less than that of agreement countries except India, and that the disclosure level of Japan and Canada is higher than that of the European Union, and that the GHG disclosure levels are not the same among the European Union countries.

Secondly, the institutional factors have important influence on environmental information disclosure. Romi (2010) tested the motivation and reason for voluntary disclosure of carbon accounting information of companies. Also based on annual questionnaire of the carbon disclosure project (CDP), he analyzed the influence of multinational difference on environmental accounting disclosure in different countries and the sample companies are those who apply to join CDP during 2002-2006. The aim of the study is to make an inspection whether environmental information disclosure level is related to legal and financial structure of a country. His study found that market structure of the country where a company locates has a significant relationship with enhanced disclosure; while legal structure has nothing to do with increase in carbon accounting disclosure. Ball \& Craig (2010) also think that institutional factors can affect environmental accounting problems in different countries. From a viewpoint of new system theory, they studied social and environmental accounting problems of Canada and England under the background of different systems.

Thirdly, scholars also believe that social factors can influence environmental information disclosure. Weidman (2002), based on the planned behavior theory of Ajzen (1991), studied the factors that influence the production and disclosure of environmental liabilities using application decision model, from the perspective of individual decision makers. The results show that the aims of report and disclosure of environmental liabilities are obviously affected by social factors and personal factors. In addition, pollution performance disclosure will be affected by political, economic, cultural and other factors. Some studies have examined the effects of these variables on pollution performance (Buhr \& Freedman, 2001; Freedman \& Jaggi, 2005).

Finally, some scholars believe that the factor of enterprise itself will also have impact on environmental information disclosure. For example, Freedman \& Jaggi (2010) found that pollution disclosure is related to firm scale. Romi (2010) studied the driving factors of environmental trade disclosure as well as market reaction to the disclosure. The results show that the degree of disclosure is relevant to factors such as enterprise industry, trading type, enterprise environmental performance and market financing needs.

Environmental information disclosure reflects the trustee responsibility of enterprises and helps to reduce the problem of environmental information asymmetry. Compared to other research perspectives, literatures of environmental accounting research based on information disclosure are relatively more in quantity and its theoretical basis and empirical research is comparatively mature. Among them, there are a great many researches on influencing factors of information disclosure. However, the conclusions are not the same as a result of different angles and sizes. In addition, the researches are relatively less on the decision-making mechanism of making information disclosure of a company and how investors respond to the information that the company discloses.

\subsection{Development from the Perspective of Cost Management}

From internal control and management of cost, environment costs can provide managers specific internal environment information, help them make environmental decisions and thus take effective control and management over environmental costs, which is beneficial for enterprises to reduce costs and solve environmental problems. Lawrence \& Cerf (1995) divided the study of environmental accounting into the perspective of management and cost accounting and the perspective of financial accounting and reporting. The difference between the two perspectives is that the cost management perspective focuses on use of internal 
information and control of environmental cost; while the external environment financial report emphasizes particularly on information disclosure to shareholders or the public. Environmental cost management did not play its real effect in the initial development period, and most of the data is employed by the management but not disclosed to shareholders (Mathews, 2000). The research objective of many literatures on environmental cost management is to improve the profits of the enterprise rather than to improve the environment, but it also can play the roll of preventing environmental costs and losses (Mylonakis \& Tahinakis, 2006). In recent years, more and more scholars have realized the importance of environmental cost management, Burritt \& Saka (2006) argued that environmental cost management is a relatively new environmental management tool, which can be used to trace and track environmental cost and the flowing of the natural (physical) environment.

From the perspective of research on cost management of environmental accounting, the emphasis is on how to confirm environmental costs, how to control the costs and how to use the costs in environmental decision-making. Some scholars studied the confirmation and measurement of environment cost. Beer \& Friend (2006) held that environmental cost is the most important element of environmental accounting, and divided it into internal cost and external cost for discussion. Herbohn (2005) argued that the lack of appropriate measuring technique limits the development of full cost environmental accounting (FCEA). He made an FCEA experiment on public forest managed by the Australian government based a loss reporting system. There are also scholars who studied the calculation and selection of discount rate of environmental cost (Sumaila \& Waiters, 2005; Kunsch et ai., 2008). Among them, Kunsch, Ruttiens and Chevalier (2008) studied how to calculate the value of the discount rate when calculating the NPV of the total cost in long-term projects taking the management of a nuclear waste project as an example, They think that Black-Scholes formula can well evaluate the risk of the project and thus can use options approach to determine the discount rate of the environment project through the classical B - S pricing formula. In addition, some scholars discussed through cost-benefit analysis approach whether the measures enterprises take on environmental protection can bring economic benefits, or what environmental protection measures can make their environment cost minimum. For example, Mobus (1997) tested the relationships between pollution situation, economic performance and the resuming of cost disclosure in oil refining industry. Lhmann (2009) discussed through case analysis the application of the cost-benefit principles and the requirements of carbon accounting technology in the Kyoto protocol. Mylonakis \& Tahinakis (2006) also put forward an expanded Cost-Benefit Analysis (CBA) model that takes into account time factor for the environment cost analysis.

In the present researches of environmental accounting, research based on the cost management perspective emphasizes particularly on techniques and methods in internal management and cost control, and is mainly used to provide environmental decision-making basis for managers. In the existing literatures, cost-benefit principle is a basic principle widely adopted in environmental cost management. However, there is no authoritative method or unified requirement in measurement technology and control method due to different situations and purposes.

\subsection{Development from the Perspective of Behavior Science}

With constant expansion of researches in environmental accounting, some scholars attempt to make innovation and exploration theoretically on environmental accounting from the perspective of organizational behavior science, and put forward a new interpretation for research on environmental accounting theory. The perspective explains the environmental and economic relations between enterprises and the society, and its operation rules and interaction as well through studying the rules of establishment, operation, change and development of social organizations.

Lounsbury (1997, 2008), Dillard et al. (2004) and Ball \& Craig (2010) make an analysis on society and environmental accounting from an angle of institutional theory. Bail \& Craig (2010) argued that the theory especially new institutionalism provides "a main research paradigm in organizational sociology" They developed the institutional analysis of organizations, and applied the four-quadrant analysis method put forward by Lounsbury $(1997,2008)$ to the research on environmental accounting problems in Canada and England under the background of different systems, so as to raise a standardization perspective and study the institutional change theory and the social environment accounting theory.

Macintosh (1997) and Moore (2010) tried to adopt structural theory to study accounting and EU Emissions Trading System (EUETS). The structural theory has been applied to the management accounting system, which is firstly built by Anthony Giddens a social theorist in the 1970s. Its goal is to build a kind of concept system that can explain the social system and include the transition condition. The basic assumption of the theory is that any complete social theory must include two parts: conduct (the subjective actions of a man with self consciousness) and structure (the structural assets from social structure of individuals and groups that act and interact). The 
structural property occurs at the same time in three aspects: signification, domination and legitimation. The signification structure is semantic rules used to create a signification; the domination structure is resources used to create a power; the legalization structure is values and codes of conduct that produce morals. These three aspects in social system are tightly woven together and can't be split, which influence together the interactions between social activities and actors in an organization and system and limit and force the actors to acquire cooperation needed to maintain social order. Moore (2010) argued that structural theory can help researchers understand the development of emission rights trading system, and explain the role of structural theory in understanding environmental accounting practices by inspecting the structure correlations between signification, domination and legitimation produced by the emission rights trading system (ETS).

Ball (2007) applied social movement and organization theory to environmental accounting. He elaborated how environmental accounting is used by enterprises in response to environmental problems, and applied a test hypothesis framework put forward by Zald et a1. (2005) to study the operation of social environment accounting, and discussed the deficiency of the traditional legitimacy theory and the theory of organizational change through case study analysis of Canada. He thought that the environment movement can significantly promote social change, enhance our attention to environment issues and help us evaluate the interaction between environment movement and enterprises.

The perspective based on behavior science explains the use of resources and the impact of organization on the environment from an angle of behaviors and changes of organizations, which is the successful application of interdisciplinary theory in the study of environmental accounting. Interpreting and analyzing environmental accounting from the perspective of behavior science can provide theoretical guidance for the behaviors of enterprises or the government. However, the research perspective is still in the stage of attempt and exploration, and has different statements and understandings on environmental accounting owing to different disciplines and different academic opinions and academic preferences of the researchers, and at the same time, the logical connections between each theory still need further perfection.

\section{Reviews and Enlightenment to China}

Through reviewing and analyzing the new research progress of environmental accounting, it can be seen that, although in recent years the research on environmental accounting theory is developing continuously and new ideas constantly emerge, but these ideas are relatively independent, therefore it is difficult for environmental accounting theories to have a unified and authoritative theoretical explanation on the whole. From the aspect of content, due to different methods and purposes, these researches have many independent and innovative perspectives and are more and more in depth, which enriches the basic theory of environmental accounting in many aspects. The corresponding empirical researches also provide empirical tests and research directions for theoretical research and practical operation.

From the above research perspectives that explain the related problems of environmental accounting, they are independent on the surface, but there are certain intrinsic logic relations between each perspective. In a strategic view, there are indivisible relations between enterprises and the society and economy. The sustainable perspective reflects the interdependent and promote-each-other relations between the three parties, and indicates the historical responsibility and development direction of environmental accounting in the macroscopic level; While enterprises as a microeconomic subject, whose pollution produces negative externalities to the society, economy and other enterprises, therefore need to solve the problem of environment pollution in a viewpoint of externalities theory; In addition, enterprises externally need to disclose and report their environmental information to their shareholders and the public, and internally also need to undertake internal environment control and environment cost management, so researches in the information disclosure perspective and cost management perspective can complement each other to a certain extent, At the same time, behaviors and changes of the enterprises also affect the resource utilization and environment decision-making. If the sustainable perspective reflects the requirements of economic sustainable development to enterprises, the behavior science perspective embodies the influence and effects of behaviors of enterprises, social organizations or system to economy. In the future study, researchers may try to unify all the perspectives to form a complete theoretical framework which covers all aspects of environmental accounting, so as to provide strong theoretical support for the development of environmental accounting.

The research on environmental accounting of China began in the 1990s. In 1992, famous accounting scholars Ge Gushu and Li Ruoshan published a thesis titled "A New Ideological Tend in the Western Accounting Theory in the 1990s: Green Accounting Theory", which marks the start of systematic research on environmental accounting in China. During nearly twenty years after that, China's environmental accounting researches have achieved 
great progress. At present, the domestic researches mainly focus on the basic theory of environmental accounting, environment information disclosure, emission rights trading accounting and environment cost management etc. Among them, basic theory of environmental accounting mainly studies the definition, nature, target, object, hypothesis, element, basic principles and reports of environmental accounting. For example, Chen Yugui (1998), Yuan Guangda (2010) et a1 studied the theoretical framework of environmental accounting, and put forward and constructed the basic system of environmental accounting. The research on environment information disclosure mainly discusses contents, mode and system of disclosure. For instance, Li Jianfa, Xiao Hua (2002) constructed an enterprise environment report framework that conforms to the requirements of the sustainable development strategy of China; Also scholars tried to make empirical test over influencing factors of environmental information disclosure, such as Tang Yali, Chen Zili (2006), Shu Yue (2010), Wu Dejun (2011), and test on value correlation of environmental information disclosure, such as Li Zheng (2006), Jiang Linfeng (2010), etc. Researches on emission rights trading accounting mainly discuss the confirmation and measurement of emission rights, emission rights trading and pricing. For example, Zhou Yihong (2005), Zhou Zhifang, Xiao Xu (2010) et al studied the accounting treatment and information disclosure in emissions trading in China. Lin Yunhua, Feng Bing (2009) analyzed the price formation mechanism in emissions trading under the condition of a perfect competition market. Xiao Xu, Zheng Ling (2011) built a carbon accounting system of a low carbon economy. There are some scholars who begin to pay close attention to and to study environmental cost calculation and environmental management. For example, Feng Qiaogen (2011) constructed an environmental cost analysis framework combining with environmental policy and related laws and regulations of China. These studies discussed environmental accounting from different respects, achieved considerable research achievements, and promoted the development in academic research of environmental accounting in China

However, there is no denying that the domestic research on environmental accounting started very late and that there are some differences between the domestic and foreign researches. First of all, China's carbon emission rights market has not been complete and perfect with inactive market trading and less price information of actual transaction, which leads to the result that research on valuation and pricing of carbon emission rights is still relatively backward. Secondly, in the aspect of environmental information disclosure, there are literatures that analyze the influence of system factors and environment policies on environmental accounting in Japan, US, Australia and other countries, but there are no research of this kind in China; What's more, there are no unified indicators on environmental performance in China, which hinders the research on the relationship between environmental performance and information disclosure and economic performance. In addition, in the aspect of application of environment cost management, foreign studies have put the cos-benefit principle into specific application. By contrast, most of researches in this area in China still stay in theoretical research level, which makes environment management accounting not play its real effect. Finally, there is no concept of sustainable accounting put forward in China at present and related research on combining behavioral science with environmental accounting is basically in blank.

According to the analyses of the gap between the domestic and foreign researches and considering the specific situations in China, some future research directions are put forward as follows: (1) Study the valuation and pricing method of carbon emission rights, establish and perfect China's carbon emission rights trading market, and construct trading system and pricing mechanism of carbon emission rights suitable for the situations of China. (2) Explore an environment performance evaluation or rating system fit for the actual situations of listed companies in China and study the influencing factors of their environment performances. (3) Extend the research on environment management accounting to the level of practical application, and solve the problems in practice of how enterprises to determine the discount rate and total cost of pollution control projects, how to make decisions in controlling pollution or purchasing emission rights and how to establish internal management, evaluation or incentive mechanisms to promote the realization of reduction target of the enterprises.

\section{References}

Ball, A. (2007). Environmental accounting as workplace activism. Critical Perspectives on Accounting, 18, 759-778. http://dx.doi.org/10.1016/j.cpa.2006.04.005

Bebbington, J., \& Larrinaga-Gonzalez, C. (2008). Carbon trading: accounting and reporting issues. European Accounting Review, 17, 697-717. http://dx.doi.org/10.1080/09638180802489162

Beck, A. C., Campbell, D., \& Shrives, P. J. (2010). Content analysis in environmental reporting research:Enrichment and rehearsal of the method in a British-German context. The British Accounting Review, 42, 207-222. http://dx.doi.org/10.1016/j.bar.2010.05.002

Blanco, E., Rey-Maquieira, J., \& Lozano, J. (2009). The economic impacts of voluntary environmental 
performance of firms: a critical review. Journal of Economic Surveys, 23, 462-502. http://dx.doi.org/10.1111/j.1467-6419.2008.00569.x

Burritt, R. L., \& Saka, C. (2006). Environmental management accounting applications and eco-eficiency: case studies from Japan. Journal of Cleaner Production, 14, 1262-1275. http://dx.doi.org/10.1016/j.jclepro.2005.08.012

Chen, Y. G. (1998). The first international guidelines on environmental accounting and reports: records of 15th session of intergovernmental expert groups on international accounting and reporting standard of the United Nations. Accounting Research, 5, 1-8.

Davis, L. W., \& Muehlegger, E. (2010). Do Americans consume too little natural gas? An empirical test of marginal cost pricing. The RAND Journal of Economics, 41, 791-810. http://dx.doi.org/10.1111/j.1756-2171.2010.00121.x

Dillard, J., Brown, D., \& Marshall, R. S. (2005). An environmentally enlightened accounting. Accounting Forum, 29, 77-101. http://dx.doi.org/10.1016/j.accfor.2004.12.001

Feng, Q. G. (2011). Environment cost management seen from KD paper companies. Accounting Research, 10, $88-95$.

Fleischman, R. K., \& Schuele, K. (2006). Green accounting: A primer. Journal of Accounting Education, 24, 35-66. http://dx.doi.org/10.1016/j.jaccedu.2006.04.001

Freedman, M. (2010). Global warming disclosures: impact of Kyoto Protocol across countries. Journal of International Financial Management and Accounting, 22, 46-90. http://dx.doi.org/10.1111/j.1467-646X.2010.01045.x

Frost, G. R. (2007). The introduction of mandatory environmental reporting guidelines: Australian evidence. Abacus, 43, 190-216. http://dx.doi.org/10.1111/j.1467-6281.2007.00225.x

Ge, J. P., \& Li, R. S. (1992). A new ideological tend of the western accounting theory in the 1990s: green accounting theory. Accounting Research, 5, 1-6.

Georgakopoulos, G., \& Thomson, I. (2005). Organic salmon farming: risk perceptions, decision heuristics and the absence of environmental accounting. Accounting Forum, 29, 49-75. http://dx.doi.org/10.1016/j.accfor.2004.12.002

Herbohn, K. (2005). A full cost environmental accounting experiment. Accounting, Organizations and Society, 30, 519-536. http://dx.doi.org/10.1016/j.aos.2005.01.001

Hopwood, A. G. (2009). Accounting and the environment. Accounting Organizations and Society, 34, 433-439. http://dx.doi.org/10.1016/j.aos.2009.03.002

Jiang, L. F. (2010). Research on correlation between enterprise value and its environment accounting information disclosure. Accounting Friends, 2, 79-82.

Jones, M. J. (2010). Accounting for the environment: Towards a theoretical perspective for environmental accounting and reporting. Accounting Forum, 34, 123-138. http://dx.doi.org/10.1016/j.accfor.2010.03.001

Kijima, M., Maeda, A., \& Nishide, K. (2010). Equilibrium pricing of contingent claims in tradable permit markets. The Journal of Futures Markets, 30, 559-589.

Kuasirikun, N. (2005). Attitudes to the development and implementation of social and environmental accounting in Thailand. Critical Perspectives on Accounting, 16, 1035-1057. http://dx.doi.org/10.1016/j.cpa.2004.02.004

Kunsch, P. L., Ruttiens, A., \& Chevalier, A. (2008). A methodology using option pricing to determine a suitable discount rate in environmental management. European Journal of Operational Research, 185, 1674-1679. http://dx.doi.org/10.1016/j.ejor.2006.08.014

Li, J. F., \& Xiao, H. (2002). Environment reports of the Chinese enterprises: status quo, demand and the future. Accounting Research, 4, 42-50.

$\mathrm{Li}, \mathrm{Z}$. (2006). Research on correlation between enterprise social responsibility and enterprise value: evidence from listed companies in Shanghai Market. China industrial economy, 2, 77-83.

Lohmann, L. (2009). Toward a different debate in environmental accounting: the cases of carbon and cost-benefit. Accounting, Organizations and Society, 34, 499-534. http://dx.doi.org/10.1016/j.aos.2008.03.002 
Mete, P., Dick, C., \& Moerman, L. (2010). Creating institutional meaning: Accounting and taxation law perspectives of carbon permits. Critical Perspectives on Accounting, 21, 619-630. http://dx.doi.org/10.1016/j.cpa.2010.03.006

Montgomery, W. D. (1972). Markets in licenses and efficient pollution control programs. Journal of Economic Theory, 5, 395-418. http://dx.doi.org/10.1016/0022-0531(72)90049-X

Moore, D. (2010). Structuration theory: The contribution of Norman Macintosh and its application to emissions trading. Critical Perspectives on Accounting, 6, 1-16.

Mylonakis, J., \& Tahinakis, P. (2006). The use of accounting information systems in the evaluation of environmental costs: a cost-benefit analysis model proposa1. International Journal of Energy Research, 30, 915-928. http://dx.doi.org/10.1002/er.1194

Shu, Y. (2010). Empirical study on the influence of corporate governance structure on environmental information disclosure: evidence from listed companies in Shanghai Market in 2008. Accounting Friends, 1, 81-84.

Solomon, J. F., \& Thomson, I. (2009). Satanic Mills? An illustration of Victorian external environmental accounting. Accounting Forum, 33, 74-87. http://dx.doi.org/10.1016/j.accfor.2008.07.012

Stefan, S., \& Burritt, R. L. (2010). Sustainability accounting for companies: Catchphrase or decision support for business leaders? Journal of World Business, 45, 375-384. http://dx.doi.org/10.1016/j.jwb.2009.08.002

Tang, Y. L., \& Chen, Z. L. (2006). Empirical research on status and influencing factors of environmental information disclosure of the Chinese. listed companies. Management World, 1, 158-159.

Wu, D. J. (2011). Responsibility index, business nature and environmental information disclosure. Journal of Zhongnan University of Economics and Law, 5, 49-54.

Xiao, X., \& Zheng, L. (2011). Research on construction of carbon accounting system of enterprises under low carbon economy. China's Population, Resources and Environment, 8, 55-60.

Xie, D. (2002). Green management system and environmental accounting of enterprises. Accounting Research, 1 , $48-53$.

Xu, M. L., \& Chen, Y. (2011). A research survey on emission rights pricing. Journal of Hunan University of Finance and Economics, 2, 22-25.

Yue, G. D. (2010). Research on environmental accounting and management path (1st ed.). Beijing: Economic Science Press.

Zhou, Y. H. (2005). Confirmation and measurement of elements in emission rights trading accounting. Environmental Protection, 3, 56-61.

Zhou, Z. F., \& Xiao, X. (2010). Review of international development of emission rights trading accounting and the enlightenment. Contemporary Finance, 1, 120-128.

Zhu, X. Y. (1999). A preliminary study on China's environmental accounting. Accounting Research, 4, 26-30.

\section{Copyrights}

Copyright for this article is retained by the author(s), with first publication rights granted to the journal.

This is an open-access article distributed under the terms and conditions of the Creative Commons Attribution license (http://creativecommons.org/licenses/by/3.0/). 